\title{
Induction and regulation of the IgE response
}

David B. Corry \& Farrah Kheradmand

Immunoglobulin E (IgE) is believed to be one of the major mediators of immediate hypersensitivity reactions that underlie atopic conditions such as urticaria, seasonal allergy, asthma and anaphylaxis. Factors that control IgE production are therefore essential to the pathogenesis of these important afflictions. But a complete understanding of this topic is lacking, while new data have raised questions regarding the precise role of $\mathrm{IgE}$ in atopic disease. Evolving concepts of $\mathrm{IgE}$ production and elimination are likely to clarify the importance of $\lg E$ in health and disease.

The atopic ${ }^{\star}$, or allergic, conditions constitute a familiar group of diseases of rising importance in Western societies. Seasonal allergy, urticaria and eczema are believed to share a unique mechanism of disease which involves the binding of $I g E$ antibodies to surface receptors present on a wide variety of cells, most importantly mast cells and eosinophils (Fig. 1). Crosslinking of receptor-bound IgE with antigen stimulates release of potentially toxic products that elicit the familiar signs and symptoms of atopic disease. These phenomena, called immediate or type I hypersensitivity reactions, include weal and flare eruptions of the skin (hives or urticaria) and sneezing, rhinorrhoea and conjunctival irritation (seasonal allergy). More serious conditions such as asthma (intermittent shortness of breath) and anaphylaxis (shortness of breath coupled with lowered blood pressure) are believed to share a similar pathogenesis. Although these diverse signs and symptoms are associated with disease, they originate from mechanisms that putatively serve a host-protective function. For example, IgE-dependent mechanisms may contribute to defence against immature parasites such as schistosomula $^{1}$ and may limit tissue injury induced by adult forms ${ }^{2}$ (Fig. 2).

In many individuals, the total serum IgE level correlates roughly with both disease severity and protective immunity to parasites. However, even in patients with marked disease, with serum antibody levels in excess of 100 times normal, IgE titres rarely approach baseline levels of other antibody classes such as immunoglobulin- $\gamma$ (IgG). Tight control of IgE may therefore be important to prevent potentially lethal consequences of IgE-dependent inflammation. Consequently, understanding the factors that control the serum $\operatorname{IgE}$ level becomes essential to dissecting the pathogenesis of atopic disease.

In this review we consider the complex regulation of the $\operatorname{IgE}$ response, distinguishing where possible the factors affecting antibody production and elimination. IgE production is intimately tied to subtypes of $\mathrm{T}$ cells and their cytokine products, certain pathogens, and the unique properties of the antigens, called allergens, associated with disease. Despite their equal importance in determining the serum IgE level, far less is known about the mechanisms of IgE elimination, although novel receptors at mucosal surfaces are probably involved.

\section{Helper-T-cell subsets}

The immune response is divided traditionally into two broad categories, humoral and cellular, emphasizing the distinct contributions of secreted antibodies and various effector cells, respectively. This dichotomy is increasingly difficult to maintain, however, as the essential cellular contributions to humoral immunity and humoral effects on the cellular response become apparent. Among the many

* Terms in italic font are defined in the glossary on p. B39. cells participating directly in immune responses, helper $\left(\mathrm{CD} 4^{+}\right) \mathrm{T}$ cells have emerged as essential orchestrators of both humoral and cellular events, for example by providing the necessary signals for antibody production and through activation of cellular antimicrobial machinery. Helper $\mathrm{T}$ cells are further classified into two functionally distinct effector subtypes, a concept that is now a dominant paradigm in cellular immunology and that provides an elegant framework for understanding atopic inflammation and the IgE response ${ }^{3}$. In general, these effector subtypes are mutually antagonistic; consequently, inflammatory responses tend to be dominated by the effects of one cell type over another.

Th1 (type 1 helper) and Th2 cells derive from a common precursor in response to distinct stimuli and are differentiated according to two major patterns of secreted proteins called cytokines (Fig. 2). Th1 cells secrete interleukin (IL)-2, interferon (IFN)- $\gamma$, tumour necrosis factor (TNF)- $\alpha$, lymphotoxin (LT) and other cytokines that together mobilize cellular and humoral defence mechanisms against intracellular pathogens and antagonize IgE responses. IL- 2 and IFN- $\gamma$ both suppress IgE synthesis through direct effects on B cells ${ }^{4-7}$. Although IL-12 and IL-18 are not type 1 cytokines in a strict sense, they also suppress IgE secretion, probably through induction of IFN- $\gamma^{8}$.

In contrast, Th2 cells secrete an entirely separate and functionally distinct repertoire of cytokines, including IL-4, IL-5, IL-6, IL-9 and IL-13. These cytokines seem to coordinate host defence against large, extracellular pathogens such as helminths'. Most of the characteristic features of atopy and asthma, especially IgE synthesis, result from the combined effects of type 2 cytokines and are closely associated with Th2-like cells ${ }^{10,11}$ (Fig. 2).

\section{IL-4/IL-13 expression and signalling}

IL-4, arguably the paradigmatic type 2 cytokine, is the most important cytokine mediating IgE synthesis ${ }^{6,12}$ (Fig. 3). Human ${ }^{13}$ and murine $\mathrm{e}^{14} \mathrm{~B}$ cells also synthesize IgE in response to the closely related cytokine IL-13 (ref. 15). IgE synthesis has also been observed under unusual conditions in the absence of IL-4, but with uncertain relevance to atopic disease ${ }^{16,17}$. Thus the biology of allergic disease closely parallels that of IL-4 and IL-13.

But the relevant sources of IL-4 required for IgE production remain unclear. The cellular sources of IL-4 are quite restricted, limited predominantly to $\mathrm{T}$ cells, although mast cells, basophils ${ }^{18}$ and eosinophils ${ }^{19}$ may also produce IL-4 and other cytokines. IL-13 shares a similar cellular distribution but is produced additionally by natural killer $(\mathrm{NK})$ cells $^{20}$. In some experimental systems, Th2 cells are alone sufficient to produce the IL-4 required for IgE synthesis ${ }^{21}$, but human basophils are able to elicit significant IgE production when cultured with $\mathrm{B}$ cells ${ }^{22}$. In addition, eosinophils are recruited early to sites of allergic challenge where they promptly secrete IL-4 in amounts sufficient for Th2 cell outgrowth, thus establishing a 


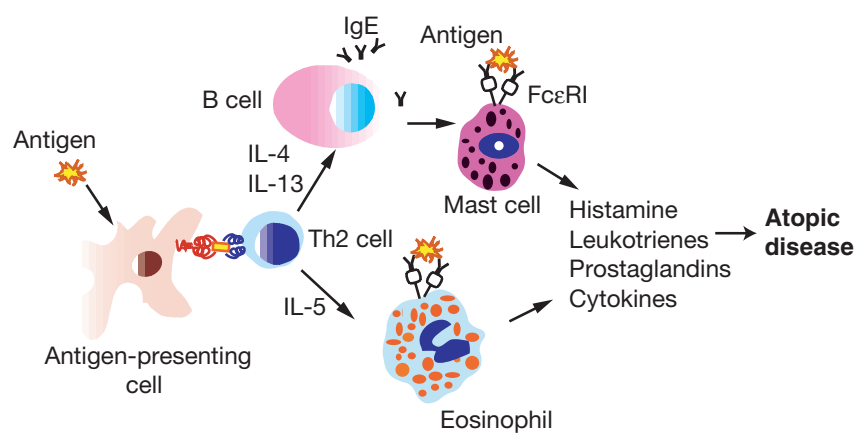

Figure 1 The type 1 hypersensitivity reaction. IgE produced by $B$ cells is captured at the cell surface by Fc epsilon receptor I (FcERI) present on mast cells and eosinophils. Cross linking of this receptor during subsequent encounter with antigen stimulates release of a variety of toxic products that together elicit atopic disease. The central role of the Th2 cell is evident: stimulated by antigen, these cells produce the IL-4 and IL-13 required for $\lg \mathrm{E}$ synthesis and the IL-5 required for eosinophil growth and differentiation. potentially important link between innate immunity and the $\operatorname{IgE}$ response $^{23}$. Natural $\mathrm{T}$ cells, $\mathrm{CD} 4^{+} \mathrm{T}$ cells expressing a restricted T-cell-receptor repertoire and the NKRP-1 surface antigen typically associated with NK cells ${ }^{24}$ release sufficient IL-4 for IgE synthesis under some conditions but are not essential for the IgE response to allergens $^{25}$.

Recent studies have emphasized intracellular pathways in the molecular control of the IgE response through IL-4/IL-13. Although the composition of the complete IL-4 and IL-13 receptors is controversial, they share the alpha chain of the IL- 4 receptor (IL$4 \mathrm{R} \alpha)^{26}$. Engagement of this moiety with either ligand initiates a signalling cascade that results in translocation to the nucleus of signal transducer and activator of transcription 6 (Stat-6) $)^{27}$ and initiation of germline epsilon messenger RNA (precursor mRNA for IgE) transcription and epsilon class switching (Fig. 3). The latter is a recombination event in which DNA encoding the antigen-binding domain of mature antibody is paired with the non-binding coding region that is specific for IgE. As determined by in vivo gene targeting, these events are dependent on IL-4R $\alpha$ and Stat-6mice that are genetically deficient in either molecule are incapable of IgE synthesis if given conventional antigen challenges ${ }^{28-30}$. Consistent with these findings, individuals with gain of function mutations in both the extracytoplasmic and intracellular domains of IL-4R $\alpha$ show enhanced IgE responses and predisposition to atopic disease ${ }^{31,32}$. Further analysis of mutations in IL- $4 \mathrm{R} \alpha$ and related genes, including their promoters and other regulatory regions, may identify additional patient subsets with dysregulation of IgE.

\section{Other signalling pathways}

Additional receptors and transcriptional regulators modulate the IgE response. The CD40 antigen is expressed on the B-cell surface after antigen recognition; engagement with its ligand (CD154; relative molecular mass 39,000) promotes IgE class switching, B-cell growth and other functions ${ }^{33}$ (Fig. 3). Crosslinking of CD40 alone is sufficient to elicit a polyclonal IgE response, but when combined with signals from the B-cell antigen receptor the response becomes antigen specific ${ }^{16}$. As with IL-4R $\alpha$, complete deficiency of CD40 abrogates in vivo IgE responses ${ }^{33,34}$. Nuclear factor kappa B $(\mathrm{NF}-\kappa \mathrm{B})$ is the probable factor initiating CD40-dependent epsilon chain transcription and synergizes with Stat- 6 to achieve maximal IgE production ${ }^{35-37}$. Gamma (IgG) transcript synthesis is also initiated through $\mathrm{CD} 40 / \mathrm{NF}-\mathrm{kB}$, but epsilon transcription is com-

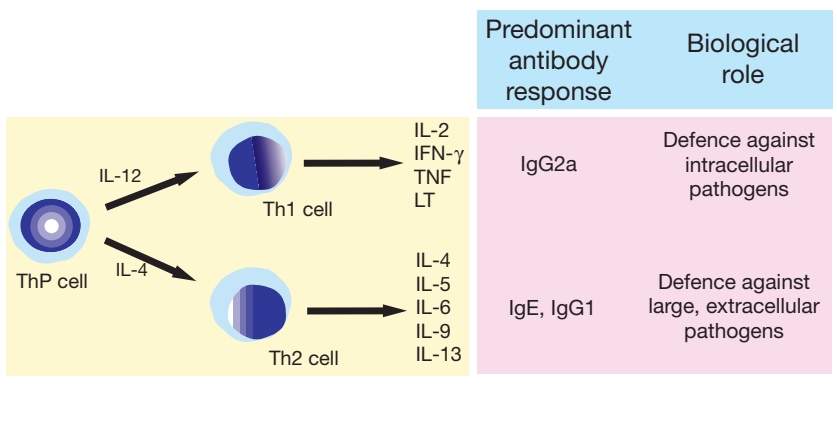

Figure 2 Overview of T-cell differentiation. Terminally differentiated helper T cells, termed Thelper cells 1 and 2 (Th1 and Th2 cells), derive from a common precursor cell (ThP cell) depending on the signals received at the time of antigen recognition. Th1 cells

emerge typically in the presence of $\mathrm{IL}-12$, whereas Th2 cells are induced by IL-4. Upon re-exposure to antigen, Th1 and Th2 cells secrete distinct patterns of cytokines that serve to activate separate immune compartments. Th1 cytokines (IL-2, IFN- $\gamma$, TNF and LT) elicit antibodies (IgG2a) and other cellular responses that together promote defence against organisms entering the intracellular compartment. In contrast, Th2 cytokines (IL-4, IL-5, IL-6, IL-9 and IL-13) promote other antibody classes (IgE, IgG1) and cellular mechanisms that protect against larger organisms that cannot be taken intracellularly.

paratively low with respect to gamma transcription, in keeping with relative serum levels of the respective antibodies. Thus, additional mechanisms may exist that limit CD40-dependent epsilon transcription, perhaps representing an important means for controlling the serum IgE level ${ }^{38}$. Other epsilon-specific transcription factors have been described, including C/EBP family members ${ }^{39}$ and BSAP/ pax-5 (ref. 40) but their in vivo relevance has yet to be determined.

Additional molecules expressed on the B-cell surface after encounter with antigen include CD80 and CD86 (formerly B7-1 and B7-2; Fig. 3). These co-stimulatory ligands engage the CD28 receptor present on $\mathrm{T}$ cells, providing an additional activation signal that is crucial to T-cell survival and cytokine secretion $^{41}$ (Fig. 3). At least under some conditions, CD86 appears to be more important for Th2 cell development, IgE production and related allergic phenomena $^{42,43}$.

\section{Nature of the antigen}

It is now clear that the biochemical properties of antigens significantly influence the direction (Th1 or Th2) of the immune response and the rise, if any, of serum IgE titres. By definition, allergens, including products of some infectious organisms such as fungi and other parasites, give rise to Th2 cells and high serum IgE levels. In contrast, other antigens, including products of bacteria, do not produce a significant rise in IgE titres but instead elicit reactivity of other antibody classes and no or few Th2 cells. Such bacteria include Listeria monocytogenes ${ }^{44}$, the agent of human listeriosis, and Mycobacterium tuberculosis, the agent of human tuberculosis. The mammalian immune system has evolved to recognize unique substances present in these organisms that influence the direction the immune response takes without necessarily being the target of $\mathrm{T}$ and $\mathrm{B}$ cells (that is, the antigen). Both listeria and mycobacteria contain conserved DNA sequences consisting of repeated cytosine and guanosine residues ( $\mathrm{CpG}$ repeats) that are uncommon in eukaryotic $\mathrm{DNA}^{45}$. These sequences are recognized by receptors on antigen-presenting cells (APCs) and trigger the release of IL-12, which suppresses IgE synthesis and attenuates the experimental asthma phenotype in mice $e^{8,46,47}$. Components of the cell walls of these and related organisms may have a similar influence on $\mathrm{APCs}^{48,49}$.

By analogy, it is likely that substances derived from fungi, parasites and other allergens direct the immune response to give rise to Th2 cells, IgE and thus atopy. Many allergens are enzymatically active, including Der $p$ I (derived from Dermatophagoides 
pteronyssinus, the common dust mite), an allergen strongly associated with childhood asthma ${ }^{50}$. This protease selectively cleaves surface CD23 of murine B cells, potentially interrupting an important negative regulator of $\operatorname{IgE}$ production $^{51}$ (see Box 1). Additional mechanisms by which proteolytically active allergens may augment atopic disease have been suggested ${ }^{52}$.

The genetic association of atopy and certain human leukocyte antigens (HLAs) indicates another feature of allergens that may predispose to the development of atopy. Under otherwise neutral conditions in vitro, murine Th2 cells develop from precursor cells according to the strength of signals received from APCs. If the signal is extremely low or high, Th2 cells tend to develop whereas intermediate signals tend to produce Th1 cells ${ }^{53,54}$. An essential component of this signal is received when class II major histocompatibility complex (MHC) molecules (analogous to HLAs in humans) interact with the antigen receptor of $\mathrm{CD} 4^{+} \mathrm{T}$ cells (Figs 1, 3). Allergenic peptides with low or high affinity for MHC molecules would be expected to confer relatively weak or strong signals through the same T-cell receptor, respectively, facilitating Th2 cell outgrowth and thus atopy.

\section{Allergen exposure history}

Similarly, peptides in very low abundance, which is typical of many allergens, would be expected to load incompletely into MHC molecules regardless of binding affinity. Weak presentation of peptides on this basis may also bias T-cell development towards IL-4 production, and thus atopy.

The route of exposure to allergen might also influence the magnitude of the IgE titre and its stability with time. Evidence indicates that antigen administered through the respiratory route is highly immunogenic, with a propensity to induce allergic inflammation. In contrast, antigen encountered through other routes, especially intravenously and orally, is more likely to induce immunologic unresponsiveness or tolerance, the latter condition being a state in which the immune system fails to respond (or responds only transiently) to potentially recognizable antigen and cannot be induced to respond on subsequent challenge. The factors that make the respiratory immune response less susceptible to tolerance induction are not entirely clear. Immune surveillance is very efficient in the lungs, and necessarily so given their importance as barriers against infections. APCs, particularly dendritic cells (also called Langerhans cells in the skin), are a critical part of this defence mechanism. These 'professional' APCs are potent inducers of immunity through their array of surface molecules (including CD80, CD86 and MHC class II molecules) and secreted substances (including IL-12) that influence both the strength and the direction of the resulting inflammatory response ${ }^{55}$. Recent studies demonstrate that airway dendritic cells underlie the Th2 polarity exhibited in airway immune responses ${ }^{56,57}$ and may induce Th2 cell development through a new pathway that does not involve IL-4 (ref. 58).

\section{IgE receptors and binding factors}

The regulation of $\operatorname{IgE}$ is associated intimately with specific receptors and other binding factors. CD23 seems to be the most important receptor affecting IgE production, while additional receptors at mucosal surfaces, so far poorly described, may be responsible for elimination of most IgE.

Fc $\in$ RI. Although essential to the biology of IgE-mediated disease, the role of the high-affinity receptor for IgE, FceRI, in the regulation of serum IgE levels seems to be minimal. FceRI binds IgE at very low concentrations $\left(K_{\mathrm{a}}=10^{9} \mathrm{M}^{-1}\right)$, greatly prolonging the in vivo half-life of $\operatorname{IgE}^{59}$. Furthermore, crosslinking of FceRI substantially

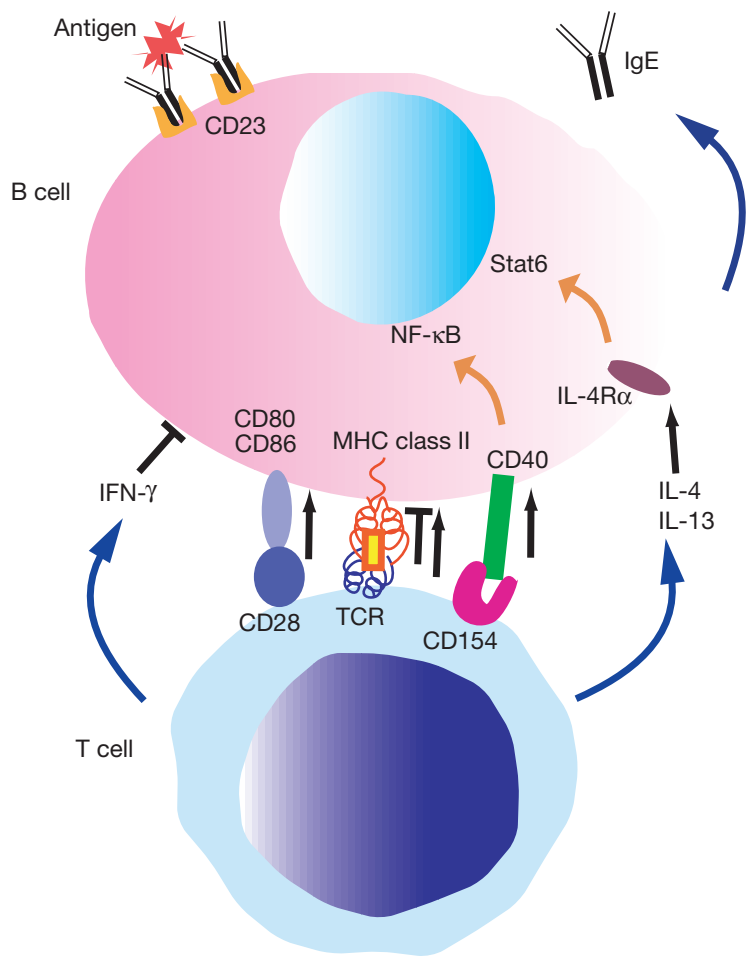

Figure 3 Molecular control of the lgE response. Although several cell types have the potential to interact with $B$ cells to promote IgE production, T cells are probably most relevant. A stimulatory effect is indicated by $\rightarrow$; an inhibitory effect by $\dashv$. Antigen presented through MHC class II molecules to the T-cell receptor (TCR) can be either stimulatory or inhibitory depending on the nature of the antigen and other factors. CD86CD28 (and perhaps CD80-CD28) and CD40-CD154 interactions promote lgE production through direct effects on T cells and B cells, respectively. Although many cytokines affect $\mathrm{IgE}$ production, IFN- $\gamma$ is probably the most important negative regulator while $\mathrm{IL}-4$ and $\mathrm{IL}-13$, both ligands for $\mathrm{IL}-4 \mathrm{R} \alpha$, are the most potent inducers. Although many transcription factors are probably involved, Stat- 6 , through IL-4R $\alpha$, and NF- $\mathrm{B}$, through CD40, directly promote lgE production by initiating epsilon transcript synthesis and class switching. The effects of CD23 are mixed, as described in Box 1 
upregulates its own expression, indicating a mechanism for augmenting the biological effects of $\operatorname{IgE}$ where antigen is present. However, baseline IgE levels and the ability to mount a robust IgE response after immunization are not affected in the complete absence of FceRI (J.-P. Kinet, personal communication). But as emphasized elsewhere in this supplement, care should be taken when attempting to extrapolate these experimental data to human disease. CD23. The second major IgE receptor was identified as a binding activity present on cultured human B cells and B-cell lines. Binding studies revealed this receptor to have a 100-1,000-fold lower affinity for $\operatorname{IgE}\left(K_{\mathrm{a}}=10^{6}-10^{7} \mathrm{M}^{-1}\right)$ than the previously identified Fc $\in \mathrm{RI}$ on mast cells and basophils; consequently, the receptor was termed the low-affinity IgE receptor or FceRII. Later studies confirmed its identity with an antigen associated with B-cell differentiation, CD23. Aside from binding IgE, CD23 shares little in common with FceRI and does not participate directly in type I hypersensitivity reactions. Although controversial, CD23 seems to serve principally as a negative regulator of IgE synthesis but may augment IgE production under some conditions. A model for the complex functions of CD23 is described in Box 1.

Other IgE receptors and binding factors. An unusual family of T-cell-derived IgE binding factors has been described that may significantly influence the IgE response ${ }^{60}$. The family is divided into either IgE-potentiating or IgE-suppressive factors based on their ability to augment or inhibit IgE responses, respectively. Although derived from the same gene, different modifications seem to confer the functional differences. These modifications are determined by two additional T-cell products-glycosylation inhibitory factor (GIF) and glycosylation enhancing factor (GEF). Administration of GIF to allergen-challenged mice suppresses IgE responses ${ }^{61}$, but the regulatory effects of GIF and GEF in human atopic disease, particularly in comparison with other IgE-regulating factors, are currently unknown. Consequently, the importance of IgEpotentiating and IgE-suppressive factors remain to be established.

Although the preceding discussion has focused entirely on the negative and positive factors affecting IgE production, equally important factors determine elimination of IgE, but these are far less well understood. Human IgE binds to additional immunoglobulin receptors, including FcyRII and Fc $\gamma$ RIII, which may mediate phagocytosis (and degradation) of IgE complexed with antigen $^{62}$. Although this route may aid in the elimination of antigen-antibody complexes, it probably does not participate in the maintenance of basal serum IgE levels, which consist primarily of uncomplexed antibody.

Both extravascular and intravascular catabolic pathways have been identified that account for loss or degradation of serum $\operatorname{Ig} \mathrm{E}^{63,64}$, although the nature of these mechanisms remain undefined. However, a recent analysis of IgE synthesis and elimination in the parasitized gut provides significant insight ${ }^{65}$. Most IgE synthesis in response to the helminth Trichinella spiralis occurs within the wall of the rodent gut by terminally differentiated B cells called plasma cells. Antibody synthesized in this location is highly compartmentalized, with the vast majority transported into the lumen of the gut, probably as a result of an IL-4-inducible mechanism ${ }^{66}$ (Fig. 4). A similar mechanism may operate in atopic syndromes: IgE is consistently found in the airways of atopic patients ${ }^{67,68}$, prompting its classification as a secreted immunoglobulin ${ }^{69}$. Intriguingly, IgE does not bind the poly-Ig transporter required for luminal export of the only other secreted antibody, $\operatorname{Ig} \mathrm{A}^{67}$, indicating that the $\operatorname{IgE}$ transport mechanism involves distinct receptors or binding factors. IgE and IgA also share a suspiciously short serum half-life ${ }^{70}$. Although much remains to be learned, the data strongly support IgE as a secreted

\section{Box 1}

\section{The effects of CD23}

The complex biology of CD23 hinders attempts at defining its physiological relevance, which remains speculative. Depending on the immune context, CD23 may exert opposite, but not necessarily mutually exclusive, effects on the serum IgE level. Passively administered antigenIgE complexes augment subsequent antibody responses when administered to mice, including that for lgE, through binding to CD23 (refs 78-80). Presumably, antigen captured in this way is processed efficiently by $B$ cells and presented to $T$ cells for subsequent immune amplification.

However, mice entirely deficient in CD23 or with only low-level

expression show increased serum lgE levels ${ }^{81,82}$, particularly when antigen-specific lgE is measured ${ }^{83}$. These data represent the strongest

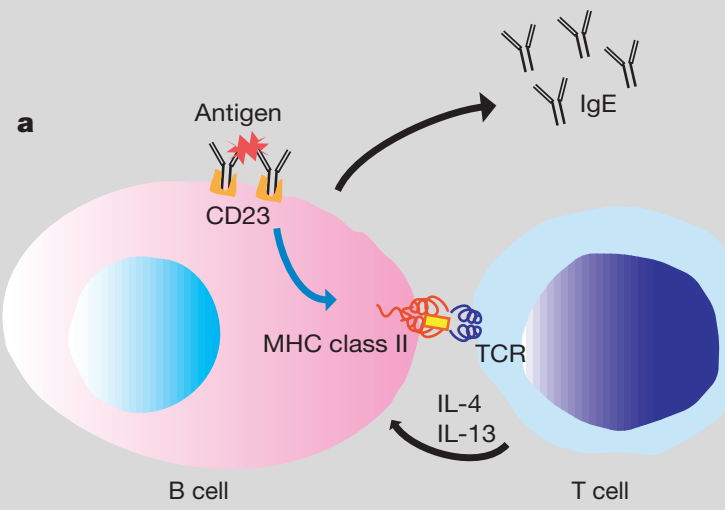

Box 1 Figure Regulation of IgE by CD23. Based on many studies, a two-part mechanism for the role of CD23 is proposed. a, At an intermediate phase in allergic immune responses, when lgE levels are sufficiently high to begin binding significantly to $C D 23$, antigen may be captured by B cells and presented to T cells, effectively augmenting IL-4/ evidence for a negative regulatory effect for CD23. The effect seems to become significant only at very high serum IgE titres, which may explain why in some studies, perhaps with less robust allergic challenges, no effect was observed ${ }^{79,84}$. A model for the combined effects of CD23 is presented in the figure below. Because CD23 serves as both a positive and a negative regulator of IgE synthesis, an elegant system potentially exists for limiting IgE production and deleterious immediate hypersensitivity responses. Importantly, the distribution of CD23 differs considerably between humans and mice, and additional data are required to verify the relevance of this model in allergic disease ${ }^{85}$.

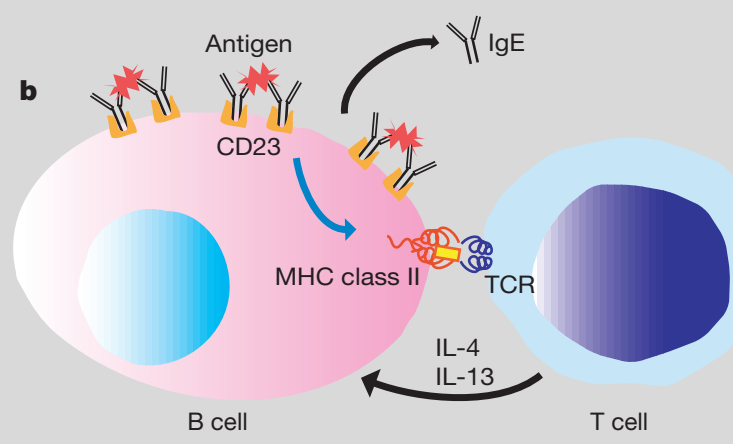

IL-13 production and the IgE response. b, At later stages, however, the increased IL-4 also facilitates expression of CD23. Combined with excess IgE and antigen, CD23 becomes extensively crosslinked, providing an inhibitory signal that eventually overrides the positive effects of antigen presentation ${ }^{86}$. 


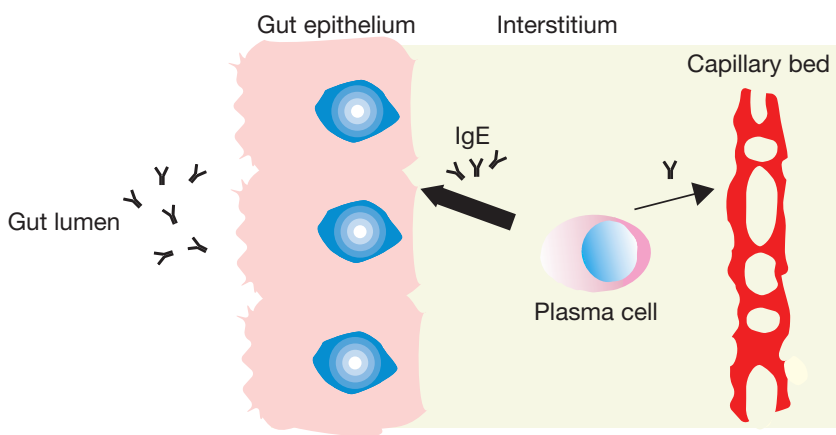

Figure 4 Elimination of lgE by extracellular transport. The majority of lgE synthesized in response to intestinal parasites occurs in the interstitium of the gut wall by terminally differentiated B cells called plasma cells. Most antibody is exported, through a poorly characterized transport system, to the lumen of the gut where presumably it participates in extracellular host defence. Only a small fraction of the total immunoglobulin pool is delivered to the blood through the capillary bed. IgE is also detected in the airways of patients with asthma, indicating a more generalized mechanism present at multiple mucosal sites. immunoglobulin and that, rather than undergoing elimination through catabolism, most IgE is simply secreted from the body at mucosal sites through a specific transport mechanism controlled by IL-4.

\section{Conclusions and future directions}

Although the advent of animal models of allergic disease and sophisticated molecular and immunologic reagents have provided a wealth of new information on induction and regulation of the $\operatorname{IgE}$ response, we are far from having a complete understanding of this important topic. In addition to gaps in existing knowledge, for example regarding mechanisms of antibody elimination, the available data present a number of intellectual and practical hurdles. Perhaps most daunting, but also most exciting, is applying the extensive knowledge gained through use of animal models to the human condition. Already the data indicate several new therapeutic avenues for amelioration of allergic disease, including strategies that target IL-4, IL-13 and their receptors.

An equally important challenge will be resolving the discrepancies that inevitably arise when results from experimental models are compared to human diseases. For example, a central paradox of allergy has been the existence of both atopic (extrinsic) and nonatopic (intrinsic) syndromes, the latter representing patients with atopic disease but no serum IgE or skin reactivity to common allergens. Several explanations have been proposed to resolve this discrepancy, the simplest being that the 'correct' antigen has simply yet to be found in non-atopic patients. Data from animal models, however, indicate a different explanation. Recently, the mechanism underlying the experimental asthma phenotype has been found to be largely antibody independent ${ }^{34,71}$, although IL-4 and IL-13 remain critical components ${ }^{72,73}$. Because these cytokines are also essential for the IgE response, the data suggest that IgE may be a marker of asthma-like disease only under some conditions. Another experimental atopic disease, anaphylaxis, may occur in the total absence of $\operatorname{IgE}^{74,75}$. These data stand in contrast to the previously demonstrated role of IgE in both experimental anaphylaxis and asthma $^{76,77}$.

How seriously do these findings challenge our long-held notions of the role of $\mathrm{IgE}$ in disease? Again, extrapolating from rodent systems to humans is potentially misleading. However, the data suggest a more complex pathogenic landscape than previously suspected, implying that the role of IgE in allergy has yet to be fully explored. The finding that IgE may be produced mucosally and exported to the lumen under the control of IL-4 indicates that serum and skin-based assays may sometimes be inadequate for investigating the role of $\mathrm{IgE}$ in atopic disease. Indeed, because most IgE may be secreted intraluminally, many non-atopic asthmatics might be found to be atopic if the IgE content of mucosal fluids were determined. Our evolving concepts of IgE regulation will remain important tools as we begin reassessing the role of $\operatorname{IgE}$ in health and disease.

David B. Corry and Farrah Kheradmand are in the Department of Medicine, Baylor College of Medicine, Houston, Texas 77030, USA.

1. Gounni, A. S. et al. High-affinity IgE receptor on eosinophils is involved in defence against parasites. Nature 367, 183-186 (1994)

2. Jankovic, D. et al. Fc epsilonRI-deficient mice infected with Schistosoma mansoni mount normal Th2-type responses while displaying enhanced liver pathology. J. Immunol. 159, 1868-1875 (1997).

3. Abbas, A. K., Murphy, K. M. \& Sher, A. Functional diversity of helper T lymphocytes. Nature 383, 787-793 (1996).

4. Lack, G. et al. Nebulized but not parenteral IFN-gamma decreases IgE production and normalizes airways function in a murine model of allergen sensitization. J. Immunol. 152, 2546-2554 (1994).

5. Coffman, R. L. \& Carty, J. A T cell activity that enhances polyclonal IgE production and its inhibition by interferon- $\gamma$. J. Immunol. 136, 949 (1986).

6. Pene, J. et al. IgE production by normal human lymphocytes is induced by interleukin 4 and suppressed by interferons $\alpha, \gamma$ and prostaglandin $\mathrm{E}_{2}$. Proc. Natl Acad. Sci. USA 85, 6880 (1988).

7. Nakanishi, K. et al. IL-2 inhibits IL-4-dependent IgE and IgG1 production in vitro and in vivo. Int. Immunol. 7, 259-268 (1995).

8. Yoshimoto, T. et al. LPS-stimulated SJL macrophages produce IL-12 and IL-18 that inhibit IgE production in vitro by induction of IFN-gamma production from CD3intIL-2R beta+ T cells. J. Immunol. 161, 1483-1492 (1998).

9. Locksley, R. M. Th2 cells: help for helminths. J. Exp. Med. 179, 1405-1407 (1994).

10. Robinson, D. S. et al. Predominant TH2-like bronchoalveolar T-lymphocyte population in atopic asthma. N. Engl. J. Med. 326, 298-304 (1992).

11. Parronchi, P. et al. Allergen- and bacterial antigen-specific T-cell clones established from atopic donors show a different profile of cytokine production. Proc. Natl Acad. Sci. USA 88, 4538-4542 (1991).

12. Finkelman, F. D. et al. IL-4 is required to generate and sustain in vivo IgE responses. J. Immunol. 141, 2335-2341 (1988)

13. Punnonen, J. et al. Interleukin 13 induces interleukin 4-independent IgG4 and IgE synthesis and CD23 expression by human B cells. Proc. Natl Acad. Sci. USA 90, 3730-3734 (1993).

14. Emson, C. L., Bell, S. E., Jones, A., Wisden, W. \& McKenzie, A. N. Interleukin (IL)-4-independent induction of immunoglobulin (Ig)E, and perturbation of $\mathrm{T}$ cell development in transgenic mice expressing IL-13. J. Exp. Med. 188, 399-404 (1998).

15. Minty, A. et al. Interleukin-13 is a new human lymphokine regulating inflammatory and immune responses. Nature 362, 248-250 (1993).

16. Ferlin, W. G. et al. CD40 signaling induces interleukin-4-independent IgE switching in vivo. Eur. J. Immunol. 26, 2911-2915 (1996).

17. Morawetz, R. A. et al. Interleukin (IL)-4-independent immunoglobulin class switch to immunoglobulin (Ig)E in the mouse. J. Exp. Med. 184, 1651-1661 (1996).

18. Seder, R. A. et al. Production of interleukin-4 and other cytokines following stimulation of mast cell lines and in vivo mast cells/basophils. Int. Arch. Allergy Appl. Immunol. 94, 137-140 (1991).

19. Ying, S. et al. Expression of IL-4 and IL-5 mRNA and protein product by CD4+ and CD8+ T cells, eosinophils, and mast cells in bronchial biopsies obtained from atopic and nonatopic (intrinsic) asthmatics. J. Immunol. 158, 3539-3544 (1997).

20. Hoshino, T., Winkler-Pickett, R. T., Mason, A. T., Ortaldo, J. R. \& Young, H. A. IL-13 production by NK cells: IL-13-producing NK and T cells are present in vivo in the absence of IFN-gamma. J. Immunol. 162, 51-59 (1999).

21. Schmitz, J. et al. Induction of interleukin 4 (IL-4) expression in T helper (Th) cells is not dependent on IL-4 from non-Th cells. J. Exp. Med. 179, 1349-1353 (1994).

22. Yanagihara, Y. et al. Cultured basophils but not cultured mast cells induce human IgE synthesis in B cells after immunologic stimulation. Clin. Exp. Immunol. 111, 136-143 (1998).

23. Sabin, E. A., Kopf, M. A. \& Pearce, E. J. Schistosoma mansoni egg-induced early IL-4 production is dependent upon IL-5 and eosinophils. J. Exp. Med. 184, 1871-1878 (1996).

24. Bix, M. \& Locksley, R. M. Natural T cells: cells that co-express NKRP-1 and TCR. J. Immunol. 155, 1020-1022 (1995). 
25. Brown, D. R. et al. Beta 2-microglobulin-dependent NK1. 1+ T cells are not essential for Thelper cell 2 immune responses. J. Exp. Med. 184, 1295-1304 (1996).

26. Zurawski, S. M., Vega, F. Jr, Huyghe, B. \& Zurawski, G. Receptors for interleukin-13 and interleukin- 4 are complex and share a novel component that functions in signal transduction. EMBO J. 12, 26632670 (1993)

27. Hou, J. et al. An interleukin-4-induced transcription factor: IL-4 Stat. Science 265, 1701-1706 (1994) 28. Grunewald, S. M. et al. An antagonistic IL-4 mutant prevents type I allergy in the mouse: inhibition of the IL-4/IL-13 receptor system completely abrogates humoral immune response to allergen and development of allergic symptoms in vivo. J. Immunol. 160, 4004-4009 (1998).

29. Kaplan, M. H., Schindler, U., Smiley, S. T. \& Grusby, M. J. Stat6 is required for mediating responses to IL-4 and for development of Th2 cells. Immunity 4, 313-319 (1996).

30. Shimoda, K. et al. Lack of IL-4-induced Th2 response and IgE class switching in mice with disrupted Stat6 gene. Nature 380, 630-633 (1996).

31. Mitsuyasu, H. et al. Ile50Val variant of IL4R alpha upregulates IgE synthesis and associates with atopic asthma. Nature Genet. 19, 119-120 (1998)

32. Hershey, G. K., Friedrich, M. F., Esswein, L. A., Thomas, M. L. \& Chatila, T. A. The association of atopy with a gain-of-function mutation in the alpha subunit of the interleukin-4 receptor. N. Engl. J. Med. 337, 1720-1725 (1997)

33. Kawabe, T. et al. The immune responses in CD40-deficient mice: impaired immunoglobulin class switching and germinal center formation. Immunity 1, 167-178 (1994).

34. Hogan, S. P., Mould, A., Kikutani, H., Ramsay, A. J. \& Foster, P. S. Aeroallergen-induced eosinophilic inflammation, lung damage, and airways hyperreactivity in mice can occur independently of IL- 4 and allergen-specific immunoglobulins. J. Clin. Invest. 99, 1329-1339 (1997).

35. Warren, W. D., Roberts, K. L., Linehan, L. A. \& Berton, M. T. Regulation of the germline immunoglobulin Cgammal promoter by CD40 ligand and IL-4: dual role for tandem NF-kappaB binding sites. Mol. Immunol. 36, 31-44 (1999).

36. Linehan, L. A., Warren, W. D., Thompson, P. A., Grusby, M. J. \& Berton, M. T. STAT6 is required fo IL-4-induced germline Ig gene transcription and switch recombination. J. Immunol. 161, 302-310 (1998).

37. Iciek, L. A., Delphin, S. A. \& Stavnezer, J. CD40 cross-linking induces Ig epsilon germline transcripts in B cells via activation of NF-kappaB: synergy with IL-4 induction. J. Immunol. 158, 4769-4779 (1997).

38. Strom, L., Laurencikiene, J., Miskiniene, A. \& Severinson, E. Characterization of CD40-dependent immunoglobulin class switching. Scand. J. Immunol. 49, 523-532 (1999).

39. Delphin, S. \& Stavnezer, J. Characterization of an interleukin 4 (IL-4) responsive region in the immunoglobulin heavy chain germline epsilon promoter: regulation by NF-IL-4, a C/EBP family member and NF-kappa B/p50. J. Exp. Med. 181, 181-192 (1995).

40. Qiu, G. \& Stavnezer, J. Overexpression of BSAP/Pax-5 inhibits switching to IgA and enhances switching to IgE in the I. 29 mu B cell line. J. Immunol. 161, 2906-2918 (1998).

41. Schwartz, R. H. Costimulation of T lymphocytes: the role of CD28, CTLA-4, and B7/BB1 in interleukin-2 production and immunotherapy. Cell 71, 1065-1068 (1992)

42. Keane-Myers, A. M., Gause, W. C., Finkelman, F. D., Xhou, X. D. \& Wills-Karp, M. Development o murine allergic asthma is dependent upon B7-2 costimulation. J. Immunol. 160, 1036-1043 (1998).

43. Kuchroo, V. et al. B7-1 and B7-2 costimulatory molecules activate differentially the Th1/Th2 developmental pathways: application to autoimmune disease therapy. Cell 80, 707-718 (1995).

44. Hsieh, C. S. et al. Development of TH1 CD4+ T cells through IL-12 produced by Listeria-induced macrophages. Science 260, 547-549 (1993).

45. Klinman, D. M., Yi, A. K., Beaucage, S. L., Conover, J. \& Krieg, A. M. CpG motifs present in bacteria DNA rapidly induce lymphocytes to secrete interleukin 6, interleukin 12, and interferon gamma. Proc Natl Acad. Sci. USA 93, 2879-2883 (1996).

46. Finkelman, F. D. et al. Effects of interleukin 12 on immune responses and host protection in mice infected with intestinal nematode parasites. J. Exp. Med. 179, 1563-1572 (1994).

47. Kline, J. N. et al. Modulation of airway inflammation by $\mathrm{CpG}$ oligodeoxynucleotides in a murine model of asthma. J. Immunol. 160, 2555-2559 (1998).

48. Cleveland, M. G., Gorham, J. D., Murphy, T. L., Tuomanen, E. \& Murphy, K. M. Lipoteichoic acid preparations of gram-positive bacteria induce interleukin-12 through a CD14-dependent pathway. Infect. Immun. 64, 1906-1912 (1996).

49. Oswald, I. P., Dozois, C. M., Petit, J. F. \& Lemaire, G. Interleukin-12 synthesis is a required step in trehalose dimycolate-induced activation of mouse peritoneal macrophages. Infect. Immun. 65, 1364 1369 (1997)

50. Sporik, R., Holgate, S. T., Platts, M. T. \& Cogswell, J. J. Exposure to house-dust mite allergen (Der p I) and the development of asthma in childhood. A prospective study. N. Engl. J. Med. 323, 502-507 (1990).

51. Hewitt, C. R., Brown, A. P., Hart, B. J. \& Pritchard, D. I. A major house dust mite allergen disrupts the immunoglobulin $\mathrm{E}$ network by selectively cleaving $\mathrm{CD} 23$ : innate protection by antiproteases. J. Exp. Med. 182, 1537-1544 (1995).

52. Herbert, C. A. et al. Augmentation of permeability in the bronchial epithelium by the house dust mite allergen Der p1. Am. J. Respir. Cell Mol. Biol. 12, 369-378 (1995).

53. Constant, S., Pfeiffer, C., Woodard, A., Pasqualini, T. \& Bottomly, K. Extent of T cell receptor ligation can determine the functional differentiation of naive CD4+ T cells. J. Exp. Med. 182, 1591-1596 (1995).

54. Farber, D. L., Luqman, M., Acuto, O. \& Bottomly, K. Control of memory CD4 T cell activation: MHC class II molecules on APCs and CD4 ligation inhibit memory but not naive CD4 T cells. Immunity 2, 249-259 (1995).
55. McWilliam, A. S., Nelson, D. J. \& Holt, P. G. The biology of airway dendritic cells. Immunol. Cell Biol. 73, 405-413 (1995)

56. Lambrecht, B. N., Salomon, B., Klatzmann, D. \& Pauwels, R. A. Dendritic cells are required for the development of chronic eosinophilic airway inflammation in response to inhaled antigen in sensitized mice. J. Immunol. 160, 4090-4097 (1998).

57. Stumbles, P. A. et al. Resting respiratory tract dendritic cells preferentially stimulate Thelper cell type 2 (Th2) responses and require obligatory cytokine signals for induction of Th1 immunity. J. Exp. Med. 188, 2019-2031 (1998).

58. Rissoan, M. C. et al. Reciprocal control of T helper cell and dendritic cell differentiation. Science 283, $1183-1186$ (1999).

59. Tada, T., Okumura, K., Platteau, B., Beckers, A. \& Bazin, H. Half-lives of two types of rat homocytotropic antibodies in circulation and in the skin. Int. Arch. Allergy Appl. Immunol. 48, 116131 (1975).

60. Ishizaka, K. IgE-binding factors and regulation of the IgE antibody response. Annu. Rev. Immunol. 6, 513-534 (1988).

61. Ishizaka, K. Regulation of the IgE antibody response. Int. Arch. Allergy Appl. Immunol. 88, 8-13 (1989).

62. Takizawa, F., Adamczewski, M. \& Kinet, J. P. Identification of the low affinity receptor for immunoglobulin $\mathrm{E}$ on mouse mast cells and macrophages as Fc gamma RII and Fc gamma RIII. J. Exp. Med. 176, 469-475 (1992).

63. Iio, A., Waldmann, T. A. \& Strober, W. Metabolic study of human IgE: evidence for an extravascular catabolic pathway. J. Immunol. 120, 1696-1701 (1978).

64. Dreskin, S. C., Goldsmith, P. K., Strober, W., Zech, L. A. \& Gallin, J. I. Metabolism of immunoglobulin $\mathrm{E}$ in patients with markedly elevated serum immunoglobulin E levels. J. Clin. Invest. 79, 1764-1772 (1987)

65. Negrao-Correa, D., Adams, L. S. \& Bell, R. G. Intestinal transport and catabolism of IgE: a major blood-independent pathway of IgE dissemination during a Trichinella spiralis infection of rats. J. Immunol. 157, 4037-4044 (1996).

66. Ramaswamy, K., Hakimi, J. \& Bell, R. G. Evidence for an interleukin 4-inducible immunoglobulin E uptake and transport mechanism in the intestine. J. Exp. Med. 180, 1793-1803 (1994).

67. Newcomb, R. W. \& Ishizaka, K. Physicochemical and antigenic studies on human gamma E in respiratory fluid. J. Immunol. 105, 85-89 (1970).

68. Ishizaka, K. \& Newcomb, R. W. Presence of gammaE in nasal washings and sputum from asthmatic patients. J. Allergy 46, 197-204 (1970).

69. Nakajima, S., Gillespie, D. N. \& Gleich, G. J. Differences between IgA and IgE as secretory proteins. Clin. Exp. Immunol. 21, 306-317 (1975).

70. Vieira, P. \& Rajewsky, K. The half-lives of serum immunoglobulins in adult mice. Eur. J. Immunol. 18, 313-316 (1988).

71. Corry, D. B. et al. Requirements for allergen-induced airway hyperreactivity in T and B cell-deficient mice. Mol. Med. 4, 344-355 (1998)

72. Wills-Karp, M. et al. Interleukin-13: central mediator of allergic asthma. Science 282, 2258-2261 (1998).

73. Grunig, G. et al. Requirement for IL-13 independently of IL-4 in experimental asthma. Science 282, 2261-2263 (1998)

74. Miyajima, I. et al. Systemic anaphylaxis in the mouse can be mediated largely through IgG1 and Fc gammaRIII. Assessment of the cardiopulmonary changes, mast cell degranulation, and death associated with active or IgE- or IgG1-dependent passive anaphylaxis. J. Clin. Invest. 99, 901-914 (1997).

75. Oettgen, H. C. et al. Active anaphylaxis in IgE-deficient mice. Nature 370, 367-370 (1994).

76. Dombrowicz, D., Flamand, V., Brigman, K. K., Koller, B. H. \& Kinet, J. P. Abolition of anaphylaxis by targeted disruption of the high affinity immunoglobulin E receptor alpha chain gene. Cell 75, 969976 (1993).

77. Oshiba, A. et al. Passive transfer of immediate hypersensitivity and airway hyperresponsiveness by allergen-specific immunoglobulin (Ig) E and mice. J. Clin. Invest. 97, 1398-1408 (1996).

78. Campbell, K. A., Lees, A., Finkelman, F. D. \& Conrad, D. H. Co-crosslinking Fc epsilon RII/CD23 and B cell surface immunoglobulin modulates B cell activation. Eur. J. Immunol. 22, 2107-2112 (1992).

79. Squire, C. M., Studer, E. J., Lees, A., Finkelman, F. D. \& Conrad, D. H. Antigen presentation is enhanced by targeting antigen to the Fc epsilon RII by antigen-anti-Fc epsilon RII conjugates. J. Immunol. 152, 4388-4396 (1994).

80. Fujiwara, H. et al. The absence of IgE antibody-mediated augmentation of immune responses in CD23-deficient mice. Proc. Natl Acad. Sci. USA 91, 6835-6839 (1994).

81. Gustavsson, S., Hjulstrom, S., Liu, T. \& Heyman, B. CD23/IgE-mediated regulation of the specific antibody response in vivo. J. Immunol. 152, 4793-4800 (1994).

82. Stief, A. et al. Mice deficient in CD23 reveal its modulatory role in IgE production but no role in Tand B cell development. J. Immunol. 152, 3378-3390 (1994).

83. Yu, P., Kosco-Vilbois, M., Richards, M., Kohler, G. \& Lamers, M. C. Negative feedback regulation of IgE synthesis by murine CD23. Nature 369, 753-756 (1994).

84. Haczku, A. et al. CD23 deficient mice develop allergic airway hyperresponsiveness following sensitization with ovalbumin. Am. J. Respir. Crit. Care Med. 156, 1945-1955 (1997).

85. Texido, G., Eibel, H., Le Gros, G. \& van der Putten, H. Transgene CD23 expression on lymphoid cells modulates IgE and IgG1 responses. J. Immunol. 153, 3028-3042 (1994).

86. Yokota, A. et al. Two species of human Fc epsilon receptor II (Fc epsilon RII/CD23): tissue-specific and IL-4-specific regulation of gene expression. Cell 55, 611-618 (1988). 